\title{
MÁQUINAS AGRÍCOLAS
}

\section{DESEMPENHO OPERACIONAL DE TRATOR COM TRAÇÃO DIANTEIRA AUXILIAR NA SUBSOLAGEM DE UM INCEPTISOL}

\author{
Neyton de Oliveira Miranda ${ }^{1}$, Maurício de Oliveira $^{2}$ \& Ricardo Lordelo Nunes $^{3}$ \\ RESUMO
}

Na subsolagem de um solo da ordem dos Inceptisol (Cambissolos) usando um trator com tração dianteira auxiliar, foram comparados pneus de duas idades, duas rotações do motor e duas marchas, além do uso ou não do bloqueio do diferencial. Mediram-se velocidade de deslocamento, patinagem das rodas traseiras, tempo operacional teórico e consumo de combustível por hora e por área trabalhada. O uso do bloqueio do diferencial não influiu significativamente em nenhum parâmetro estudado e o de pneus novos resultou em desempenho do trator superior em relação aos pneus desgastados, para todos os parâmetros estudados. A rotação do motor de $1.800 \mathrm{rpm}$ reduziu a patinagem e o consumo de combustível por hora e por área trabalhada em relação a $2.000 \mathrm{rpm}$, enquanto o uso da quarta marcha reduziu o tempo operacional teórico e o consumo de combustível por área trabalhada em relação à terceira marcha.

Palavras-chave: bloqueio do diferencial, desgaste dos pneus, marcha, preparo do solo

\section{PERFORMANCE OF A FRONT WHEEL DRIVE TRACTOR IN THE SUBSOILING OPERATION IN AN INCEPTISOL}

\begin{abstract}
In the subsoiling operation in an Inceptisol with a front wheel drive tractor, worn and new tyres, two engine speeds, two gear ratios and the use or not of the differential lock, were compared. Travel speed, rear wheel slip, theoretical field time, and fuel consumption per hour as well as per worked area were measured. The differential lock did not influence significantly any studied parameter. New tires were superior to worn ones for all parameters. Engine speed of $1800 \mathrm{rpm}$ reduced wheel slip, fuel consumption per hour and per hectare compared with $2000 \mathrm{rpm}$. Fourth gear reduced the theoretical field time and fuel consumption per hectare compared to third gear.
\end{abstract}

Key words: differential lock, tyre wear, gear ratio, soil tillage

Recebido em 20/09/1999, Protocolo 107/99

${ }^{1}$ Professor Adjunto, Mestre, Escola Superior de Agricultura de Mossoró, CP 137, CEP 59625 - 900, Mossoró, RN. Fone: (0xx84) 312 2100, Fax: (0xx84) 312 2499. E-mail: neyton@esam.br

${ }^{2}$ Professor Adjunto, Dr. Escola Superior de Agricultura de Mossoró. E-mail: mauricio@esam.br

${ }^{3}$ Acadêmico de Agronomia. Escola Superior de Agricultura de Mossoró 


\section{INTRODUÇÃO}

A mecanização intensiva foi introduzida recentemente na região de Mossoró, RN, em conjunto com a irrigação de culturas como o melão. Os agricultores da região necessitam realizar o preparo na época mais seca, o que exige tratores de potência elevada e várias operações de destorroamento, elevando os custos de produção. O preparo periódico em solos que apresentam alto coeficiente de expansibilidade, requer cuidados especiais, devido à alta atividade da fração argila (Ernesto Sobrinho, 1979) elevando os custos de produção.

Os custos da maquinaria agrícola são, em geral, o maior dos custos de produção, exceto da terra, podendo responder por $50 \%$ dos custos anuais, em propriedades com agricultura intensiva sob regime de irrigação (Bowers, 1992). Neste sentido, Hunt (1995) afirma que pequenas melhorias no gerenciamento das máquinas podem trazer maior retorno que grandes economias em outros custos de produção. Segundo Souza \& Milanez (1990) pode-se reduzir o consumo de combustível dos tratores, aumentando a eficiência de utilização do combustível ou reduzindo a necessidade de energia útil pelas operações agrícolas.

Através dos rodados, a eficiência de transformação da potência do motor em potência útil na barra de tração é muito baixa. Os fatores que mais influem no rendimento de tração são as condições do solo, as dimensões dos pneus, sua relação carga/pressão e o tipo de carcaça (radial/diagonal) além do ângulo e altura das garras, enquanto o máximo rendimento de tração é obtido num certo nível de patinagem das rodas motrizes e é beneficiado pelo uso de pneus adequados, tração nas quatro rodas, bloqueio do diferencial e lastragem adequada (Souza \& Milanez, 1990; Hunt, 1995).

Segundo Schlosser et al. (1992) a patinagem excessiva das rodas motrizes, devida à falta de interação entre o rodado e o solo, é um fator de perda de velocidade e é agravada pelo mau estado dos pneus. Franz (1988) afirma que os rodados pneumáticos para tração devem proporcionar aderência ao solo; para isto, a banda de rodagem possui garras cujas dimensões, principalmente a altura, variam devido a características construtivas ou por desgaste, afetando a capacidade do trator em desenvolver esforço de tração. Ortiz-Cañavate \& Hernanz (1989) salientam ser maior a capacidade de tração com maior altura de garras dos pneus-motrizes.

Elevados custos operacionais, aumento do consumo de combustível e rápido desgaste do trator se devem ao fato dos tratores brasileiros serem operados, na maioria, com altas rotações e marchas reduzidas, na faixa de potência máxima do motor. Aumenta-se a eficiência de um trator operando-o nas áreas mais favoráveis das curvas de desempenho do motor obtendo-se, através da seleção das marchas e posições do acelerador, a faixa mais econômica de torque e rotação. Há a possibilidade de se aumentar a eficiência do uso do combustível em até $17 \%$, através da troca da marcha e redução na aceleração, mantendo a mesma velocidade de deslocamento (Souza \& Milanez, 1990; Souza \& Ferreira, 1992; Hunt, 1995; Bernardes \& Balastreire, 1997). Possível economia de combustível na faixa de 15 a $30 \%$ é citada por Cordeiro et al. (1988) pelo uso de marcha adequada e redução na rotação do motor, para $80 \%$ da máxima.

A patinagem de uma roda motriz em relação à outra, devido à ação do diferencial, prejudica o desempenho do trator. Duquesne et al. (1995) citam as causas da diferença de velocidade entre as rodas-motrizes: a roda externa gira mais rápido numa curva; em condições diferentes de relevo superficial, as rodas percorrem distâncias diferentes, mesmo em linha reta; em condições diferentes de tração, a roda com pior capacidade de tração gira mais rápido; a roda com menor raio, devido à pressão desigual, carga diferenciada ou altura diferente das garras por construção ou desgaste, gira mais rápido. Goering (1992) explica que o torque desenvolvido em cada semi-árvore motriz do trator é limitado pela tração que pode ser desenvolvida pela roda correspondente, razão pela qual o torque máximo desenvolvido pelo trator é limitado ao torque que pode ser exercido pela roda com pior capacidade de tração; além disto, como o torque é igual nas duas semi-árvores, a maior potência é dirigida pelo diferencial para a roda com maior velocidade, que é a que tem a pior capacidade de tração. Para aproveitar ao máximo o torque disponível e diminuir a perda de potência, é usado o bloqueio do diferencial, mecanismo que, quando acionado, impede o movimento relativo entre as semi-árvores, resultando em velocidade igual em ambas. Desta maneira, a roda com melhor capacidade de tração transmite maior potência (Borgman et al., 1991; Goering, 1992). Segundo Marquez (1990) para aumentar o aproveitamento dos tratores é imprescindível usar, de maneira sistemática, o bloqueio do diferencial. Segundo Duquesne et al. (1995) na maioria dos casos a maior velocidade de deslocamento e, conseqüentemente, maior capacidade operacional, são obtidas com o diferencial bloqueado. Para alguns autores, o diferencial só deve ser bloqueado temporariamente quando, por falta de aderência, uma das rodas patina demais, impedindo o deslocamento normal do trator e deve ser desbloqueado cada vez que se fizer uma curva (Buckingham, 1976; Goering, 1992; Mialhe, 1980).

Este trabalho teve como objetivo determinar a influência do desgaste dos pneus, do uso do bloqueio do diferencial e da operação à rotação inferior e marcha superior às normalmente usadas, sobre o desempenho de um trator com tração dianteira auxiliar na operação de subsolagem de um solo da ordem dos Cambissolos (Inceptisol).

\section{MATERIAL E MÉTODOS}

O trabalho foi realizado na Fazenda São João Ltda., em setembro de 1996, em área previamente preparada com grade pesada, e que apresentava muitos torrões soltos, dado às características físicas do solo. O solo trabalhado pertence ao Grande Grupo dos Cambissolos Háplicos Ta Eutróficos, conforme o Sistema Brasileiro de Classificação de Solos (EMBRAPA, 1999) formado a partir da decomposição do calcário da Formação Jandaíra (BRASIL, 1971). Na Tabela 1 são apresentados a densidade do solo e o teor de umidade atual, por ocasião do preparo do solo do experimento.

Tabela 1. Densidade do solo e teor de água de um Cambissolo Háplico Ta Eutrófico, localizado na Fazenda São João, município de Mossoró, Rio Grande do Norte

\begin{tabular}{ccc}
\hline $\begin{array}{c}\text { Profundidade de coleta } \\
(\mathrm{cm})\end{array}$ & $\begin{array}{c}\text { Densidade do solo } \\
\left(\mathrm{kg} \mathrm{dm}^{-3}\right)\end{array}$ & $\begin{array}{c}\text { Umidade* } \\
\left(\mathrm{kg} \mathrm{dm}^{-3}\right)\end{array}$ \\
\hline $0-20$ & 1,39 & 8,24 \\
$20-40$ & 1,42 & 11,60 \\
$40-60$ & 1,38 & 12,60 \\
\hline
\end{tabular}


Foi utilizado um trator VALMET 148, que trabalhou com tração dianteira acionada, cuja potência máxima do motor foi de $106,6 \mathrm{~kW}$ a $2.300 \mathrm{rpm}$ e peso total de $74.970 \mathrm{~N}$. Os pneus dianteiros eram 14.9 - 26, R1, com 8 lonas e pressão interna de 179,2 $\mathrm{kPa}$ e os traseiros, 23.1 - 30, R1, com 12 lonas e pressão interna de 165,5 kPa, estavam lastrados com pesos metálicos, além de água em aproximadamente $75 \%$ do seu volume. A altura das garras dos pneus traseiros usados mostrava um desgaste de, em média, $37 \%$ em relação aos pneus novos. Foi usado um subsolador DMB de arrasto com controle remoto, com duas hastes parabólicas espaçadas $1,30 \mathrm{~m}$ e pneus para limitar a profundidade do corte, que foi mantida constante à profundidade de $50 \mathrm{~cm}$. As determinações para avaliação do desempenho do trator foram realizadas em percursos contínuos de $500 \mathrm{~m}$, e em cada percurso, foram demarcados trajetos de $50 \mathrm{~m}$ para determinar a velocidade de deslocamento e a patinagem dos pneus traseiros, em função de um número de giros conhecido, conforme descrito por Corrêa et al. (1995). O consumo horário de combustível foi determinado conforme descrito por Lanças et al. (1996); já o consumo de combustível por hectare e a capacidade operacional teórica foram calculados conforme descrito por Souza \& Ferreira (1992) considerando-se o tempo operacional teórico como o inverso da capacidade operacional teórica. $\mathrm{O}$ delineamento estatístico utilizado foi blocos inteiramente casualizados, com três repetições, em esquema fatorial $2^{4}$, enquanto os fatores estudados foram dois níveis de desgaste dos pneus (novos e usados), duas rotações do motor (1.800 e $2.000 \mathrm{rpm}$ ), duas marchas ( $3^{\mathrm{a}}$ e $4^{\mathrm{a}}$ ) e o uso ou não do bloqueio do diferencial. O processamento eletrônico para tratamento estatístico dos dados foi efetuado empregando-se o software SAEG for Windows, Versão 7, desenvolvido pela Universidade Federal de Viçosa.

\section{RESULTADOS E DISCUSSÃO}

Uma síntese do quadro de análises de variância para as características avaliadas é apresentada na Tabela 2, na qual se observa que não foram registradas diferenças estatisticamente significativas para interação entre os fatores analisados, como fonte de variação; também verifica-se que o emprego de bloqueio no diferencial do trator não afetou qualquer dessas características. Variação na rotação do motor, marcha empregada durante o preparo e o desgaste dos pneus influenciaram no rendimento do trator quando do preparo do Cambissolo estudado. Os baixos valores apresentados para o coeficiente de variação permitem inferir sobre a baixa variância e, conseqüentemente, sobre o elevado grau de precisão do experimento.

Tabela 2. Resumo das análises de variância (ANOVA) para se avaliar o desempenho de um trator com tração dianteira auxiliar, na subsolagem de um Cambissolo Háplico Ta Eutrófico na região de Mossoró, RN

\begin{tabular}{|c|c|c|c|c|c|c|}
\hline \multirow{2}{*}{$\begin{array}{l}\text { Fonte de } \\
\text { Variação }\end{array}$} & \multirow{2}{*}{$\begin{array}{l}\text { Grau de } \\
\text { Liberdade }\end{array}$} & \multicolumn{5}{|c|}{ Quadrados Médios } \\
\hline & & Velocidade & Patinagem & $\begin{array}{c}\text { Tempo } \\
\text { Operacional } \\
\text { Teórico }\end{array}$ & $\begin{array}{l}\text { Consumo } \\
\text { Horário }\end{array}$ & $\begin{array}{c}\text { Consumo por } \\
\text { Hectare }\end{array}$ \\
\hline Blocos & 2 & $0,347^{* * *}$ & $178,011^{* *}$ & $0,141^{* *}$ & $2,984^{\mathrm{ns}}$ & $7,426^{\mathrm{ns}}$ \\
\hline Bloqueio & 1 & $0,006^{\mathrm{ns}}$ & $6,690^{\mathrm{ns}}$ & $0,011^{\mathrm{ns}}$ & $0,039^{\mathrm{ns}}$ & $3,055^{\mathrm{ns}}$ \\
\hline Rotação & 1 & $0,808^{* *}$ & $293,139^{* * *}$ & $0,222^{* *}$ & $40,996^{* *}$ & $45,143^{* *}$ \\
\hline Marcha & 1 & $12,454^{* *}$ & $6,870^{\mathrm{ns}}$ & $3,938^{* * *}$ & $52,584^{* * *}$ & $201,679^{* *}$ \\
\hline Pneu & 1 & $0,239^{* *}$ & $102,726^{* * *}$ & $0,079^{* * *}$ & $3,360^{\mathrm{ns}}$ & $57,531^{* *}$ \\
\hline Resíduo & 35 & 0,028 & 13,102 & 0,011 & 0,949 & 6,765 \\
\hline C.V (\%) & & 4,44 & 18,92 & 5,02 & 6,65 & 8,47 \\
\hline
\end{tabular}

Quando se analisou o efeito isolado do desgaste dos pneus como efeito principal, os pneus novos foram superiores em todos os parâmetros avaliados; mesmo que a menor velocidade do trator com pneus usados (Figura 1) possa ser atribuída ao seu menor raio (Franz, 1988). Apenas o consumo horário de combustível (Figura 2) não diferiu significativamente, observando-se redução pronunciada na patinagem dos pneus traseiros $(14,2 \%)$ devido à maior aderência proporcionada pelos pneus novos; por outro lado, esta aderência proporcionou, além de aumento na velocidade de deslocamento, diminuição no tempo operacional teórico, demonstrando que o uso dos pneus novos economizou tempo (Figura 1); além disso o uso de pneus novos trouxe uma economia de 2,2 L (6,9\%) no consumo de combustível por hectare (Figura 2). Em experimento realizado por Franz (1988) os pneus com maior altura de garras também apresentaram melhor desempenho e o desgaste dos outros pneus em relação a eles, diminuiu seu desempenho.
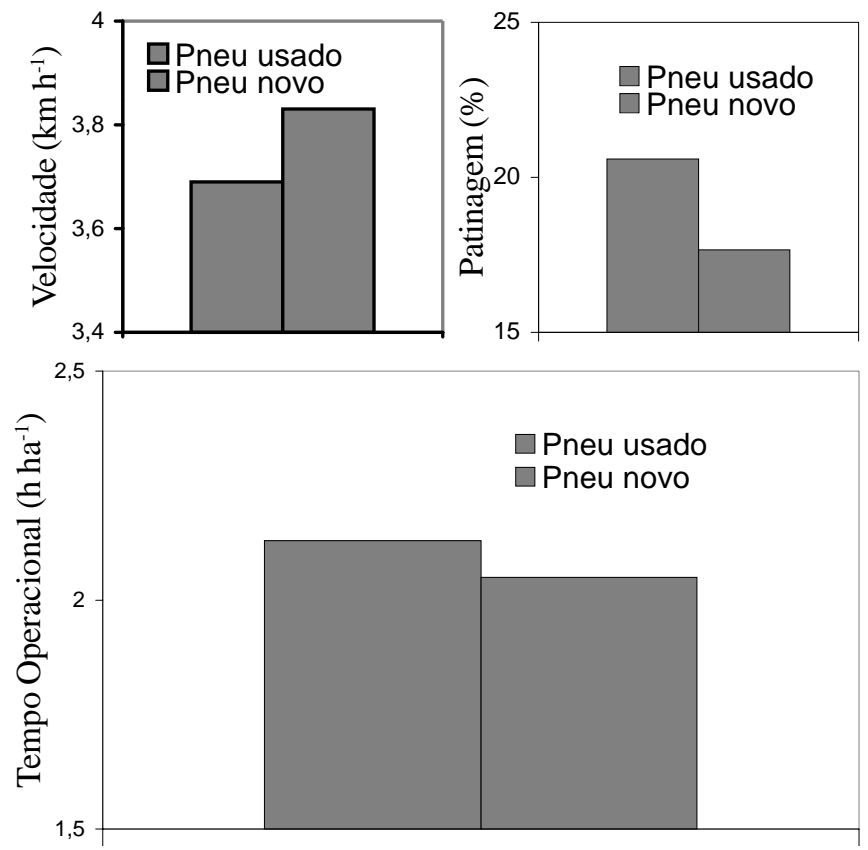

Figura 1. Desempenho de trator operando com pneus em diferentes níveis de desgaste no preparo de um Cambissolo Háplico Ta Eutrófico, na região de Mossoró, RN

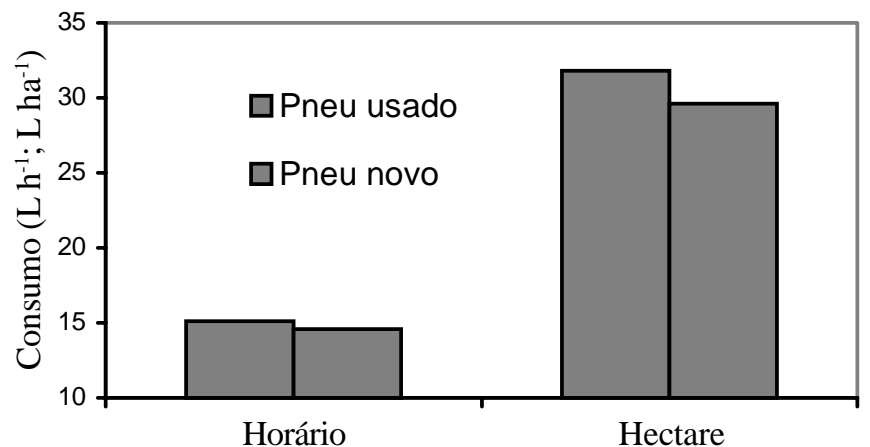

Figura 2. Consumo de combustível de trator operando com pneus novos e usados em diferentes níveis de desgaste no preparo de um Cambissolo Háplico Ta Eutrófico, na região de Mossoró, RN 
Quanto ao uso do bloqueio do diferencial e apesar da análise estatística não ter indicado diferença significativa observa-se, na Figura 3 que, quando foram analisados em separado, os pneus usados apresentaram tendência de melhoria de desempenho quando se usou o diferencial bloqueado, ou seja, em más condições de aderência dos pneus traseiros o uso do bloqueio do diferencial poderia ser vantajoso. A patinagem diminuiu em 8,8 \% (Figura 3 ) e o consumo de combustível por hectare em $4,8 \%$ (Figura 6) porém para os pneus novos, que proporcionam melhor aderência ao solo, a tendência não foi observada, razão por que não se recomenda a operação do trator com o diferencial bloqueado nessas condições, devido às restrições ao seu uso, feitas por Buckingham (1976), Mialhe (1980) e Goering (1992).
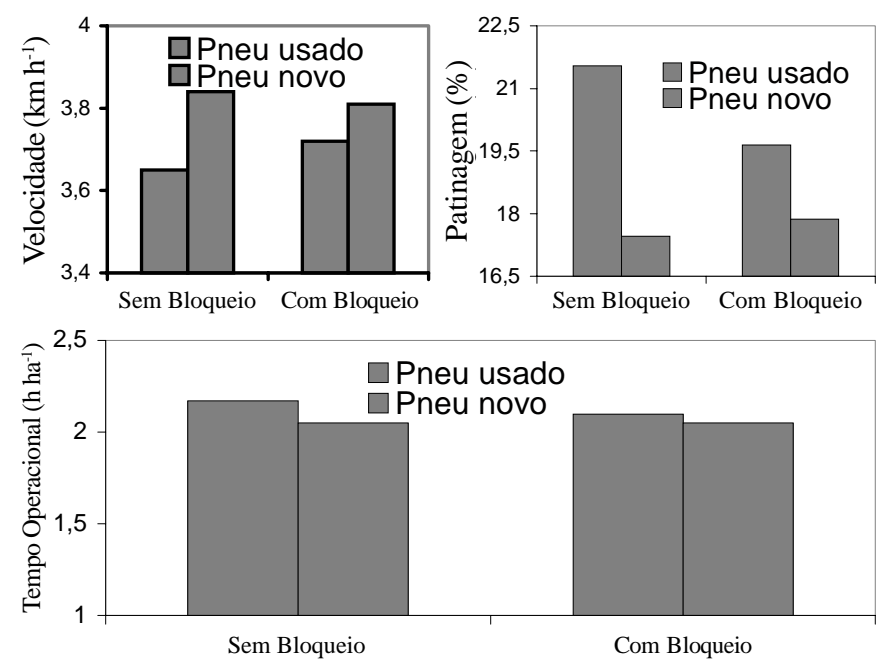

Figura 3. Efeito do uso do bloqueio do diferencial em trator operando com pneus novos e usados em diferentes níveis de desgaste no preparo de um Cambissolo Háplico Ta Eutrófico, na região de Mossoró, $\mathrm{RN}$

O efeito da rotação do motor foi analisado em separado para cada tipo de pneu (Figura 4). Quando se usou pneus desgastados na rotação de $2.000 \mathrm{rpm}$, obteve-se a maior velocidade de deslocamento e um tempo operacional teórico $6,8 \%$ menor, como esperado, porém a rotação de $1.800 \mathrm{rpm}$ foi mais vantajosa economicamente pois, além de reduzir a patinagem em 19,2\% (Figura 4), obteve-se consumo horário de combustível 12,9\% menor e consumo de combustível por hectare 2,32 L menor, ou 7\% (Figura 6). Com o uso de pneus novos, todos os parâmetros tiveram melhor comportamento, mas a tendência foi semelhante e, quando se trabalhou a $1.800 \mathrm{rpm}$, o que mais se evidenciou foi a redução de $26,9 \%$ na patinagem (Figura 4) e de 10,5\% no consumo horário de combustível (Figura 6) mas a diferença de 1,56 L a menos no consumo de combustível por hectare não foi significativa. A redução no consumo de combustível quando se opera a rotações menores que as usuais, na faixa mais econômica de operação do motor, é relatada por Cordeiro et al. (1988), Souza \& Milanez (1990), Souza \& Ferreira (1992), Hunt (1995) e Bernardes \& Balastreire (1997).

Como já foi evidenciado, a mudança de marcha durante a subsolagem afetou todas as variáveis empregadas, exceto
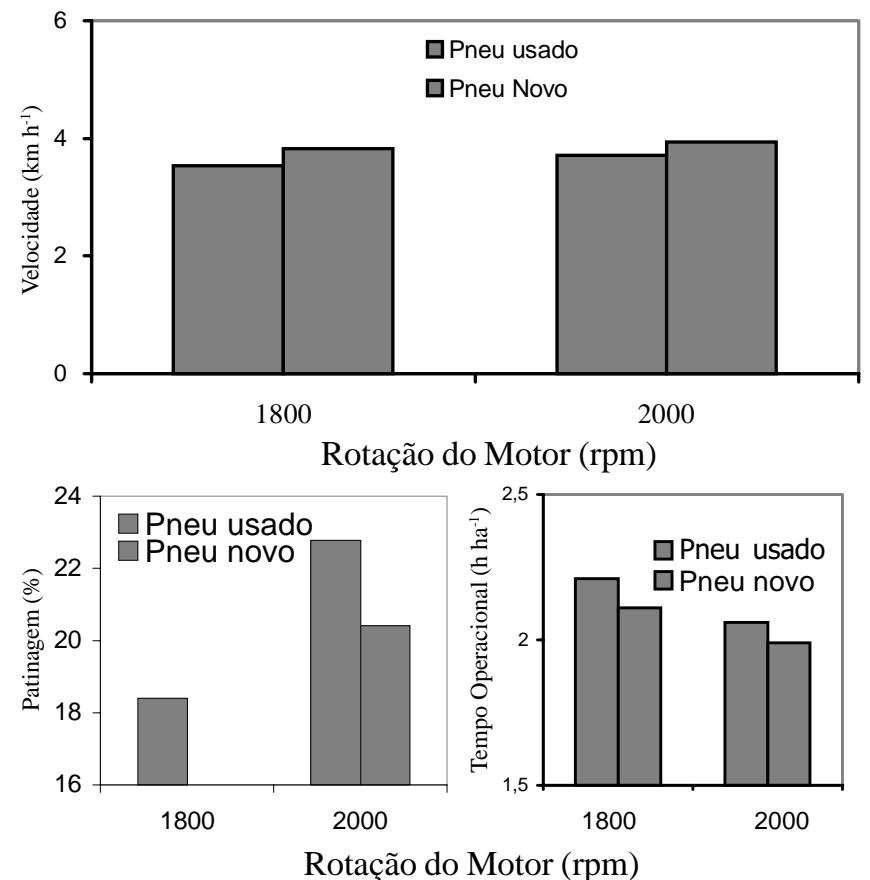

Figura 4. Efeito da rotação do motor em trator operando com pneus novos e usados em diferentes níveis de desgaste no preparo de um Cambissolo Háplico Ta Eutrófico, na região de Mossoró, RN

patinagem. Pela Figura 5 observa-se que, operando-se em $4^{\text {a }}$ marcha, há um aumento na velocidade do trator, indiferentemente se se usam pneus novos ou velhos, o que acarretou um aumento de $18,3 \%$ no consumo horário de combustível quando se usou a 4 a marcha (Figura 6); devido ao menor torque nesta marcha, o motor foi submetido a uma carga maior para tracionar o subsolador porém, além do aumento de velocidade, previsto no projeto do trator, nota-se que, com pneus desgastados, a $4^{\mathrm{a}}$ marcha diminuiu em 23,5\% o tempo operacional teórico (Figura 5) e proporcionou uma economia de combustível de $3,25 \mathrm{~L} \mathrm{ha}^{-1}$ ou 9,7\%, em relação à 3a (Figura 6); já quando se usou pneus novos, a 4a marcha reduziu o tempo operacional teórico em $24,3 \%$ (Figura 5) proporcionando uma economia de 4,95 L de combustível por hectare, ou $15,4 \%$, em relação à 3 marcha (Figura 6); isto evidencia, portanto, a superioridade dos pneus novos em relação aos desgastados, e os resultados recomendam, como mais vantajoso, operar na 4a marcha que, usada com uma rotação do motor de $1.800 \mathrm{rpm}$, seria a maneira mais econômica de se operar o trator; além disso, os resultados de patinagem dos pneus traseiros novos, quando o trator operou a 1.800 rpm (já discutidos e avaliados pela Figura 4) sugerem a possibilidade de operar numa marcha acima da 4 a marcha. Esta forma de operação com a qual se procura aumentar a capacidade operacional e reduzir o consumo de combustível, através da redução da rotação do motor até um nível ótimo e da troca de marchas, é citada como vantajosa por autores como Souza \& Milanez (1990), Souza \& Ferreira (1992), Hunt (1995) e Bernardes \& Balastreire (1997). 


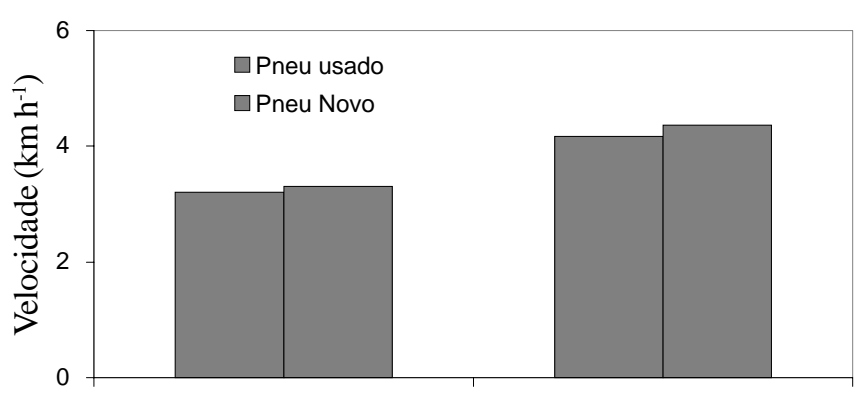

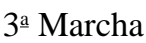
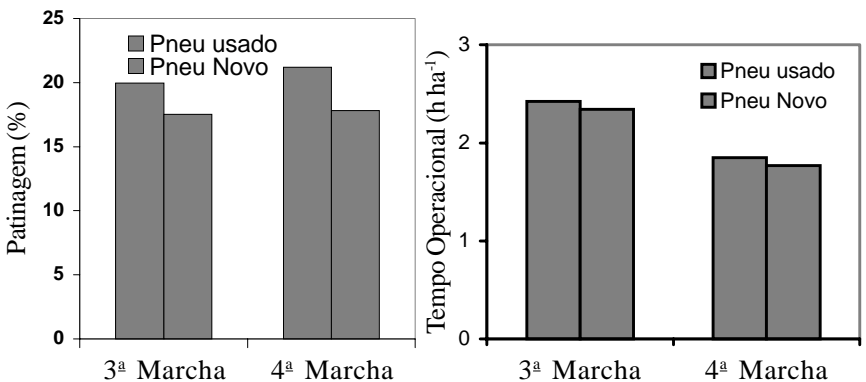

Figura 5. Efeito da marcha usada em um trator operando com pneus novos e usados em diferentes níveis de desgaste no preparo de um Cambissolo Háplico Ta Eutrófico, na região de Mossoró, RN
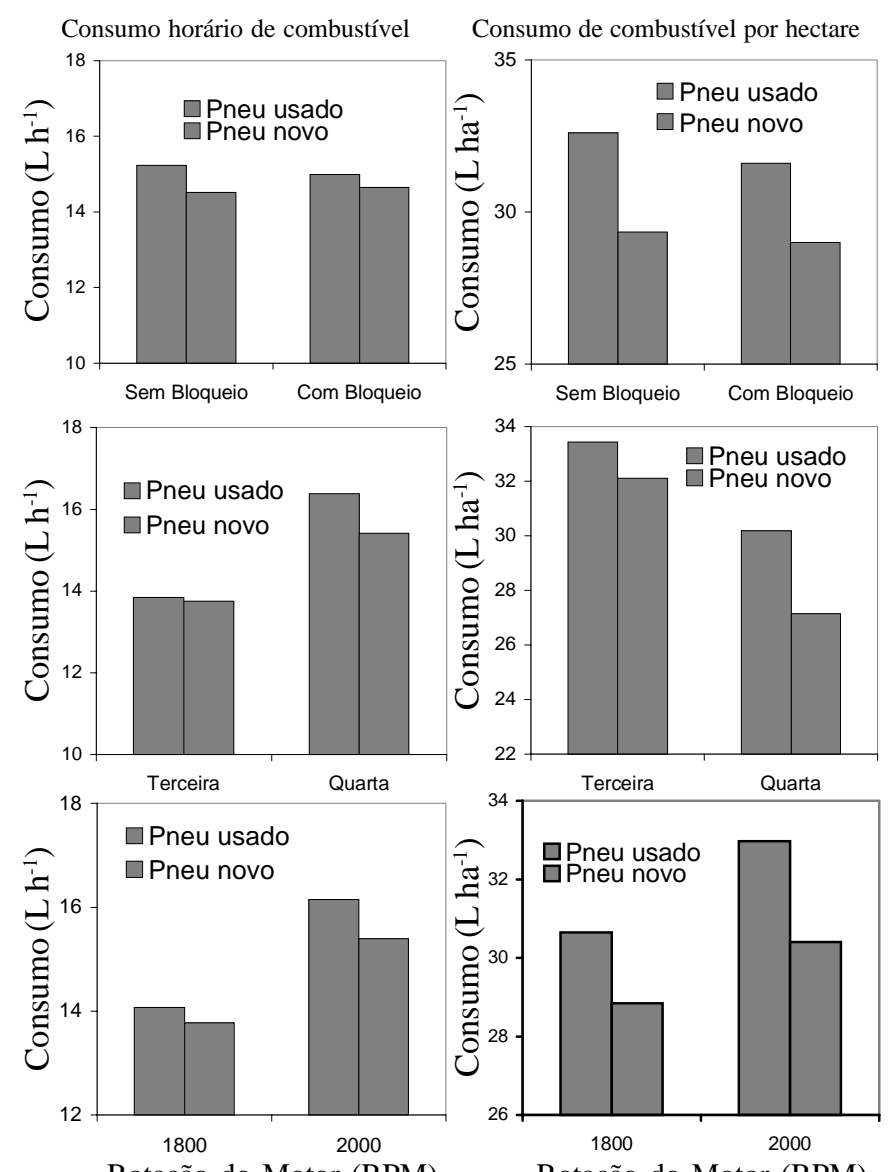

Figura 6. Consumo de combustível por um trator operando sob diferentes combinações de bloqueio do diferencial, velocidade de deslocamento e rotações do motor, usando-se pneus em diferentes níveis de desgaste, no preparo de um Cambissolo Háplico Ta Eutrófico, na região de Mossoró, RN

\section{CONCLUSÕES}

1. O desempenho do trator com pneus novos foi superior em todos os parâmetros estudados, em relação aos pneus com desgaste.

2. A operação do trator com o diferencial bloqueado não trouxe melhoria significativa para o desempenho na subsolagem.

3. A operação do trator na rotação de $1.800 \mathrm{rpm}$ do motor foi superior a $2.000 \mathrm{rpm}$, pois proporcionou uma economia de até 2,32 L de combustível por hectare.

4. A operação do trator na $4^{\mathrm{a}}$ marcha foi superior à $3^{\mathrm{a}}$ marcha, pois proporcionou uma economia de até $24,3 \%$ no tempo operacional teórico e de até 4,95 L de combustível por hectare.

5. Nas condições de operação estudadas, a melhor maneira de se operar o trator seria em $4^{\mathrm{a}}$ marcha a $1.800 \mathrm{rpm}$ no motor.

\section{REFERÊNCIAS BIBLIOGRÁFICAS}

BERNARDES, R.C.; BALASTREIRE, L.A. Determinação das curvas de iso-consumo de combustível com trator operando sobre solo agrícola. In: CONGRESSO BRASILEIRO DE ENGENHARIA AGRÍCOLA, 26, 1997, Campina Grande. Resumos... Campina Grande: Sociedade Brasileira de Engenharia Agrícola/UFPB, 1997. CD-ROM.

BORGMAN, D.E.; HAINLINE, E.; LONG, M.E. Fundamentals of machine operation: Tractors. 3. ed. Moline: Deere \& Company Service Publications, 1991. 271 p.

BOWERS, W. Machinery management. 4. ed. Moline: Deere \& Company Service Publications, 1992. 206 p.

BRASIL. Ministério da Agricultura. Levantamento exploratório-reconhecimento de solos do Estado do Rio Grande do Norte. Recife: SUDENE, 1971. 531p.

BUCKINGHAM, F. Fundamentals of machine operation: Tillage. Moline: Deere \& Company Service Publications, 1976. 368 p.

CORDEIRO, M.A.F.; SOUZA, A.P.; BENEZ, S.H. Consumo de combustível em tratores agrícolas tracionando carretas e roçadeiras montadas. In: CONGRESSO BRASILEIRO DE ENGENHARIA AGRÍCOLA, 17, 1988, Iperó. Anais... Iperó: Sociedade Brasileira de Engenharia Agrícola/CENEA, 1988. p. 328-337.

CORREIA, I.M.; MAZIERO, J.V.G.; YANAI, K. Tratores agrícolas: Cálculo da patinagem das rodas motrizes. Engenharia Rural, Piracicaba, v.6, n.2, p.63-71, 1995.

DUQUESNE, F.; KERMIS, L.; VERSCHOORE, R. Influence of the differential locking on tractor working rate: Part 1, Simulation of a single axle vehicle. Journal of Agricultural Engineering Research, Silsoe, v. 60, p.201-209, 1995.

EMBRAPA, Centro Nacional de Pesquisa de Solos. Sistema brasileiro de classificação de solos. Brasília, DF: Serviço de Produção de Informação, 1999. 412p.

ERNESTO SOBRINHO, F. Caracterização, gênese e interpretação para uso de solos derivados de calcário da região da Chapada do Apodi, Rio Grande do Norte. Viçosa: Universidade Federal de Viçosa, 1979. 133 p. Dissertação Mestrado 
FRANZ, C.A.B. Avaliação do desempenho de pneumáticos para tratores agrícolas com diferentes níveis de desgaste. Santa Maria: Universidade Federal de Santa Maria, 1988. 93 p. Dissertação Mestrado

GOERING, C.E. Engine and tractor power. 3. ed. St. Joseph: American Society of Agricultural Engineers, 1992. 539 p.

HUNT, D. Farm power and machinery management. 9. ed. Ames: Iowa State University Press, 1995. 363 p.

LANÇAS, K.P.; UPADHYAYA, S.K.; RÍPOLI, T.C. Efeito da pressão de inflação de pneus radiais no desempenho de tratores agrícolas e na compactação do solo. In: CONGRESSO BRASILEIRODEENGENHARIA AGRÍCOLA, 25, 1996, Bauru. Anais... Bauru: Sociedade Brasileira de Engenharia agrícola, 1996. CD-ROM.

MARQUEZ, L. Solotractor. Madrid: Laboreo S.A., 1990. 231 p.

MIALHE, L.G. Máquinas motoras na agricultura. v.2. São Paulo: EDUSP/USP, 1980.367 p.

ORTIZ-CAÑAVATE, J.; HERNANZ, J.L. Tecnica de la mecanización agraria. 3. ed. Madrid: Ediciones Mundi Prensa, 1989.641 p.
SCHLOSSER, J.F.; PEREIRA, C.F.; SOUZA, F.E.G.; HURTADO, R.R.; MEZZOMO, C.P.L. Equalização da patinagem provocada pela diferenciação de lastros no trabalho do trator em aração a duas velocidades. In: CONGRESSO BRASILEIRO DE ENGENHARIA AGRÍCOLA, 21, 1992, Santa Maria. Anais... Santa Maria: Sociedade Brasileira de Engenharia Agrícola/UFSM, 1992. p. 1535-1546.

SOUZA, E.G.; MILANEZ, L.F. Conservação de energia no uso de tratores na agricultura. In: CONGRESSO BRASILEIRODE ENGENHARIA AGRÍCOLA, 19, 1990, Piracicaba. Anais... Piracicaba: Sociedade Brasileira de Engenharia Agrícola/ ESALQ, 1990.p. 712-726.

SOUZA, L.F.C.; FERREIRA, O.O. Desempenho comparativo de dois tratores em dois regimes de lavração. In: CONGRESSO BRASILEIRO DE ENGENHARIA AGRÍCOLA, 21, 1992, Santa Maria. Anais... Santa Maria: Sociedade Brasileira de Engenharia Agrícola/UFSM, 1992. p. 1752-1763. 